\title{
Periarticular analgesic injection containing a corticosteroid after total hip arthroplasty may prevent deep venous thrombosis: a retrospective comparative cohort study
}

Akira Hashimoto ${ }^{1}$, Motoki Sonohata ${ }^{1 *}$, Hirohito Hirata', Shunsuke Kawano², Shuichi Eto ${ }^{1}$, Masaya Ueno ${ }^{1}$ and Masaaki Mawatari ${ }^{1}$

\begin{abstract}
Background: Of late, periarticular analgesic injection (PAl) has become a common alternative treatment for pain following total hip arthroplasty (THA). However, the systemic effects of PAl containing corticosteroids in patients subjected to THA have not been investigated. This study evaluated the analgesic efficacy and systemic effects of PAl containing a corticosteroid in patients subjected to THA.

Methods: This single-center, retrospective cohort study enrolled patients undergoing unilateral, primary THA. A total of 197 patients (200 hips) were included in the final analyses, with 87 hips in the PAl group and 113 hips in the control group. Numeric Rating Scale (NRS) and laboratory data were assessed preoperatively and on postoperative days (POD) 1 and 7. Pearson's correlation coefficients were obtained to assess the correlations between the D-dimer level on POD 7 and each outcome measure on POD 1.

Results: The postoperative white blood cell count (WBC) was significantly higher in the PAl group than in the control group. Postoperative NRS, creatine phosphokinase (CK), and C-reactive protein (CRP) levels were significantly lower in the PAI group. D-dimer levels were significantly lower in the PAI group on POD 7. Postoperative aspartate transaminase (AST), alanine aminotransferase, blood urea nitrogen, and creatinine levels were within reference ranges. D-dimer levels on POD 7 showed a significant negative correlation with WBC on POD $1(r=-0.4652)$ and a significant positive correlation with the NRS score and AST, CK, CRP, and D-dimer levels on POD $1(r=0.1558$, $0.2353,0.2718,0.3545$, and 0.3359 , respectively).

Conclusions: PAI containing a corticosteroid may be an effective treatment for pain and inflammation after THA, and it does not seem to cause drug-induced liver or kidney injury. Moreover, corticosteroid PAI can may accelerate early ambulation, which prevents the elevation of postoperative D-dimer levels, and may reduce the risk of deep venous thrombosis.
\end{abstract}

Keywords: Periarticular analgesic injection, Total hip arthroplasty, Corticosteroid, Anti-inflammation, D-dimer, Triamcinolone acetonide

\footnotetext{
* Correspondence: epc9719@yahoo.co.jp

'Department of Orthopaedic Surgery, Faculty of Medicine, Saga University, Nabeshima 5-1-1, 849-8501 Saga, Japan
}

Full list of author information is available at the end of the article

C C The Author(s). 2021 Open Access This article is licensed under a Creative Commons Attribution 4.0 International License, which permits use, sharing, adaptation, distribution and reproduction in any medium or format, as long as you give appropriate credit to the original author(s) and the source, provide a link to the Creative Commons licence, and indicate if changes were made. The images or other third party material in this article are included in the article's Creative Commons licence, unless indicated otherwise in a credit line to the material. If material is not included in the article's Creative Commons licence and your intended use is not permitted by statutory regulation or exceeds the permitted use, you will need to obtain permission directly from the copyright holder. To view a copy of this licence, visit http://creativecommons.org/licenses/by/4.0/. The Creative Commons Public Domain Dedication waiver (http://creativecommons.org/publicdomain/zero/1.0/) applies to the data made available in this article, unless otherwise stated in a credit line to the data. 


\section{Background}

Total hip arthroplasty (THA) is a common, standardized, highly cost-effective surgical procedure [1]. However, earlier reports have found a patient dissatisfaction rate following THA of up to 11\% [2]. Postoperative pain is an important factor affecting patients' satisfaction with THA [2, 3]. Moreover, poorly managed postoperative pain can cause chronic postoperative pain [4]. Therefore, effective treatment of postoperative pain remains an important challenge for physicians [3]. Conventionally, many strategies have been applied to reduce postoperative pain, including peripheral nerve block, systemic morphine, and continuous epidural analgesia [5]. Recently, periarticular analgesic injection (PAI) has become a common alternative treatment for pain management following THA [6]. However, mixed opinions and conflicting results regarding PAI for pain management following THA have been reported [6-8]. PAI usually consists of local analgesics that may be combined with corticosteroids, opioids, epinephrine, or nonsteroidal anti-inflammatory drugs (NSAIDs) and then diluted with normal saline [7]. Several reports have been published regarding the analgesic effect of PAI containing corticosteroids and the anti-inflammatory effect of PAI containing NSAIDs in THA [9-11]. However, to the best of our knowledge, the systemic effects of PAI containing corticosteroids in patients subjected to THA have not been investigated.

In this study, we aimed to investigate the systemic effects of PAI containing corticosteroids and its efficacy for reducing postoperative pain in patients undergoing primary THA.

\section{Methods}

This was a single center, retrospective cohort study. The study protocol adhered to the ethical guidelines of the 1975 Declaration of Helsinki, and the study was approved by the Ethics Committee Saga University Hospital. All patients provided opt-out informed consent prior to participation in this study.

A total of 254 patients (288 hips) who had undergone unilateral primary THA at our hospital between May 2019 and January 2020 were initially included. We implemented PAI at our hospital beginning in September 2019 for patients undergoing THA. Thus, patients who underwent THA from May 2019 to August 2019 were considered to be the control group, and patients who received THA between September 2019 and January 2020 comprised the PAI group. One hundred and forty patients (151 hips) were enrolled in the control group and 114 patients (137 hips) were enrolled in the PAI group. In the control group, we excluded 1 hip with hip ankylosis, 7 hips with femoral head necrosis, 5 hips with rapidly destructive coxarthrosis, 4 hips with osteotomy around the hip joints, 3 hips with post-traumatic arthritis of the hip joint, 2 hips with high hip dislocation, 1 hip with an intraoperative fracture, 2 hips with collagen diseases, 3 hips with medical complications, and 10 hips that lacked sufficient perioperative Numeric Rating Scale (NRS) data [12]. In the PAI group, we excluded 2 hips with hip ankylosis, 6 hips with femoral head necrosis, 2 hips with rapidly destructive coxarthrosis, 3 hips with osteotomy around the hip joint, 4 hips with posttraumatic arthritis of the hip joint, 5 hips with high hip dislocation, 2 hips with collagen diseases, 8 hips of patients with diabetes, and 18 hips that lacked sufficient perioperative NRS data. Finally, 197 patients (200 hips) with primary hip osteoarthritis or secondary hip osteoarthritis due to developmental dysplasia of the hip joint were enrolled. Thus, the analyses included a total of 113 hips (112 patients) in the control group and 87 hips (85 patients) in the PAI group (Table 1).

Anesthesia and surgery followed standardized procedures. All patients received spinal anesthesia with $0.5 \%$ isobaric bupivacaine in a single shot using a 27-gauge penciltype spinal needle at the lower lumbar level. Midazolam (2-3 mg, intravenous injection) was administered for conscious sedation if needed. In all patients, $1 \mathrm{~g}$ of tranexamic acid and $1 \mathrm{~g}$ of cefazolin were administered intravenously before the skin incision to control surgical bleeding and prevent surgical site infection. All THA procedures were performed with a cementless femoral stem (910 PerFix or AG-PROTEX stem [Kyocera, Tokyo, Japan]) and an acetabular cup (910 PerFix or AG-PROTEX cup [Kyocera, Tokyo, Japan]) via a posterolateral approach. The suction drain was removed 1 day after surgery. In all patients, $1 \mathrm{~g}$ of cefazolin was administered intravenously before surgery in the operating room and three times within the time period between the patient's return to the ward and the morning after surgery; and $30 \mathrm{mg}$ of edoxaban tosilate hydrate was administered orally once per day from postoperative day (POD) 1 to POD 7.

In the PAI group, injections were performed after total hip prosthesis implantation and prior to closure. The PAI was a $41 \mathrm{ml}$ solution containing $20 \mathrm{~mL}$ of $5 \mathrm{mg}$ /

Table 1 Demographic data for the PAI and control groups

\begin{tabular}{llll}
\hline & Control group & PAI group & $P$ value \\
\hline Number of hips (patients) & $113(112)$ & $87(85)$ & \\
Sex (females), n (\%) & $95(85)$ & $77(91)$ & 0.4163 \\
Age (years) & $65.3 \pm 8.8$ & $65.9 \pm 10.3$ & 0.6784 \\
BMl (kg/m ${ }^{2}$ ) & $24.1 \pm 3.2$ & $24.2 \pm 4.9$ & 0.6117 \\
Operation time (minutes) & $47.8 \pm 9.0$ & $51.1 \pm 19.9$ & 0.4364 \\
Intraoperative blood loss (g) & $244.3 \pm 90.0$ & $248.6 \pm 119.1$ & 0.8815 \\
Postoperative blood loss (g) & $164.3 \pm 133.1$ & $149.0 \pm 98.5$ & 0.641 \\
\hline
\end{tabular}

Values are expressed as the mean \pm standard deviation. $P A /$ periarticular analgesic injection, $B M I$ body mass index 
$\mathrm{mL}$ levobupivacaine, $1 \mathrm{~mL}$ of $40 \mathrm{mg} / \mathrm{mL}$ triamcinolone acetonide (Kenacort- $A^{\bullet}$ Intramuscular/Intraarticular Aqueous Suspension Injection; Bristol-Myers Squibb K.K., Tokyo, Japan), and $20 \mathrm{~mL}$ normal saline. The surgeon injected $10 \mathrm{~mL}$ of the solution into the capsule, $21 \mathrm{~mL}$ into the gluteus and external rotators, and $10 \mathrm{~mL}$ into the fatty layer.

The postoperative analgesic protocol was same for both groups. The patients received $50 \mathrm{mg}$ of flurbiprofen axetil (Ropion'; Kaken Seiyaku Co., Ltd., Tokyo, Japan) as a continuous intravenous infusion within the first $24 \mathrm{~h}$ after surgery (total dose $=200 \mathrm{mg}$ ); acetaminophen $\quad$ (Acelio ${ }^{\circ}$ Intravenous Injection; Terumo Corporation, Tokyo, Japan) at $1,000 \mathrm{mg}$ for patients with body weight $\geq 50 \mathrm{~kg}$ (total dose $=4000 \mathrm{mg}$ ) or $15 \mathrm{mg} / \mathrm{kg}$ for patients with a body weight $<50 \mathrm{~kg}$ as an intravenous infusion every $6 \mathrm{~h}$ during the first $24 \mathrm{~h}$ after surgery; and celecoxib (Celecox; Astellas Pharma Inc., Tokyo, Japan) $200 \mathrm{mg}$ orally twice daily following an initial dose of $400 \mathrm{mg}$ as the standard analgesic protocol. As rescue drugs, a $50 \mathrm{mg}$ diclofenac sodium suppository (Voltaren ${ }^{\circ} \mathrm{SUPPO}^{\circ}$; Novartis Pharma K.K., Tokyo, Japan) or $15 \mathrm{mg}$ of pentazocine (intramuscular) (Sosegon Injection; Maruishi Pharmaceutical Co., Ltd., Tokyo, Japan) were administered.

Postoperative antithrombotic therapy was the same for both groups and included the following: edoxban (Lixiana $\odot$, Daiichi Sankyo Company, Tokyo, Japan) for 7 days after surgery, wearing compression stockings during hospital stay, and early ambulation. The normal daily dose of endoxban was $30 \mathrm{mg}$ (or $15 \mathrm{mg}$ when patients weighed less than $50 \mathrm{~kg}$; or $30 \mathrm{ml} / \mathrm{min} \leq$ creatinine clearance $\leq 50 \mathrm{ml} / \mathrm{min}$ or 75 years and over) taken once orally. Walking training within the allowable pain range was started without weight-bearing limitations, beginning 1 day after surgery.

Sex, age, body mass index (BMI), operative time, intraoperative blood loss, and postoperative blood loss were assessed. Intraoperative blood loss was calculated based on the contents of the suction bottle and the change in the weight of the used surgical sponges. Postoperative blood loss was calculated based on the contents of the drain.

The primary outcome was the maximum pain level, assessed before surgery, on POD 1, and on POD 7. The patient's pain level was assessed using the NRS. The NRS is a segmented numeric version of the visual analog scale in which a respondent selects a whole number (integers $0-10)$ that best reflects the intensity of their pain.

The secondary outcomes were the laboratory data obtained pre-surgery, on POD 1, and on POD 7, which were assessed using perioperative routine blood tests. Laboratory data included the white blood cell count (WBC), aspartate transaminase (AST), alanine aminotransferase (ALT), creatine phosphokinase (CK), blood urea nitrogen (BUN), creatinine $(\mathrm{Cr}), \mathrm{C}$-reactive protein (CRP), and D-dimer levels. Reference ranges for the la-

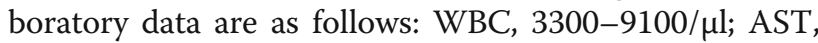
10-35 U/l; ALT, 5-40 U/l; CK, 40-160 U/l; BUN, 8$20 \mathrm{mg} / \mathrm{dl} ; \mathrm{Cr}, 0.40-0.70 \mathrm{mg} / \mathrm{dl}$; CRP, $0.00-0.30 \mathrm{mg} / \mathrm{dl}$; and D-dimer, $0.00-1.00 \mu \mathrm{g} / \mathrm{ml}$.

\section{Statistical analyses}

All numerical data are expressed as the mean \pm standard deviation. All analyses were performed using JMP ${ }^{\circ}$ Pro software (version 14.2.0, SAS Institute Japan Ltd, Tokyo, Japan). We employed the Wilcoxson signed-rank test to compare BMI, operation time, intra- and postoperative blood loss, pre- and postoperative laboratory data, and pre- and postoperative NRS between the two groups. A Chi-squared test was used to compare the male:female proportion between the two groups. A Student's $t$-test was used to compare the mean age between the two groups. The Steel-Dwass test was used to compare the perioperative data (NRS and laboratory data) within each group. Pearson's correlation coefficients were obtained to assess the correlations between the D-dimer level on POD 7 and each outcome on POD 1. The level of significance was set at $\mathrm{p}<0.05$. Post-hoc analysis of the study was performed (effect size $=0.5$, two-sided alpha $=0.05$, sample size $=113$ and 87 ), and the calculated power was 0.93 .

\section{Results}

There were no significant differences between the control and PAI groups in terms of age, sex, BMI, intra- or post-operative blood loss, or operation time (Table 1).

Preoperative NRS scores in the PAI group were significantly higher than those in the control group, whereas postoperative NRS scores in the PAI group were significantly lower than those in the control group (Table 2; Fig. 1i).

Table 3; Fig. 1a-h show the comparisons of laboratory values between the control and PAI groups and the comparison of perioperative laboratory data in each group. The postoperative WBC was significantly higher in the PAI group than in the control group, and within the PAI group the WBC was significantly higher on POD 7 than before surgery (Table 3; Fig. 1a) Postoperative CK levels were significantly lower in the PAI group than in the control group. Within the PAI group, CK levels were significantly lower on POD 7 than before surgery (Table 3; Fig. 1d). Postoperative CRP levels were lower in the PAI group than in the control group (Table 3; Fig. 1g). Seven days postoperatively, D-dimer levels were significantly lower in the PAI group than in the control group (Table 3; Fig. 1h). Postoperative AST, ALT, BUN, and Cr levels were within the reference ranges in both groups (Table 3; Fig. 1b, c, e and f). 
Table 2 Comparison of NRS scores between the PAI and control groups

\begin{tabular}{lccc}
\hline & Control group $(\boldsymbol{N}=\mathbf{1 1 3})$ & PAl group $(\boldsymbol{N = 8 7 )}$ & \\
\hline NRS scores & & & \\
Preoperative & $5.5 \pm 2.1$ & $6.3 \pm 2.1$ & 0.004 \\
1 day postoperative & $4.7 \pm 2.4$ & $3.8 \pm 2.4$ & 0.0051 \\
7 days postoperative & $2.3 \pm 1.7$ & $2.2 \pm 4.7$ & 0.0114 \\
\hline
\end{tabular}

Values are expressed as the mean \pm standard deviation. PAl periarticular analgesic injection, NRS numeric rating scale

In all hips, combining both groups, D-dimer levels on POD 7 had a significant negative association with the WBC on POD $1(r=-0.4652 ; p<0.0001)$. D-dimer levels on POD 7 had a significant positive association with the NRS score and AST, CK, CRP, and D-dimer levels on POD $1(r=0.1558,0.2353,0.2718,0.3545$, and 0.3359 , respectively; Table 4).

\section{Discussion}

To the best of our knowledge, this study is the first to investigate the effect of PAI containing a corticosteroid on laboratory data following THA. Our findings indicate that corticosteroid PAI is an effective treatment for pain and inflammation after THA. Corticosteroid PAI may lead to early ambulation, reduced D-dimer levels, and,

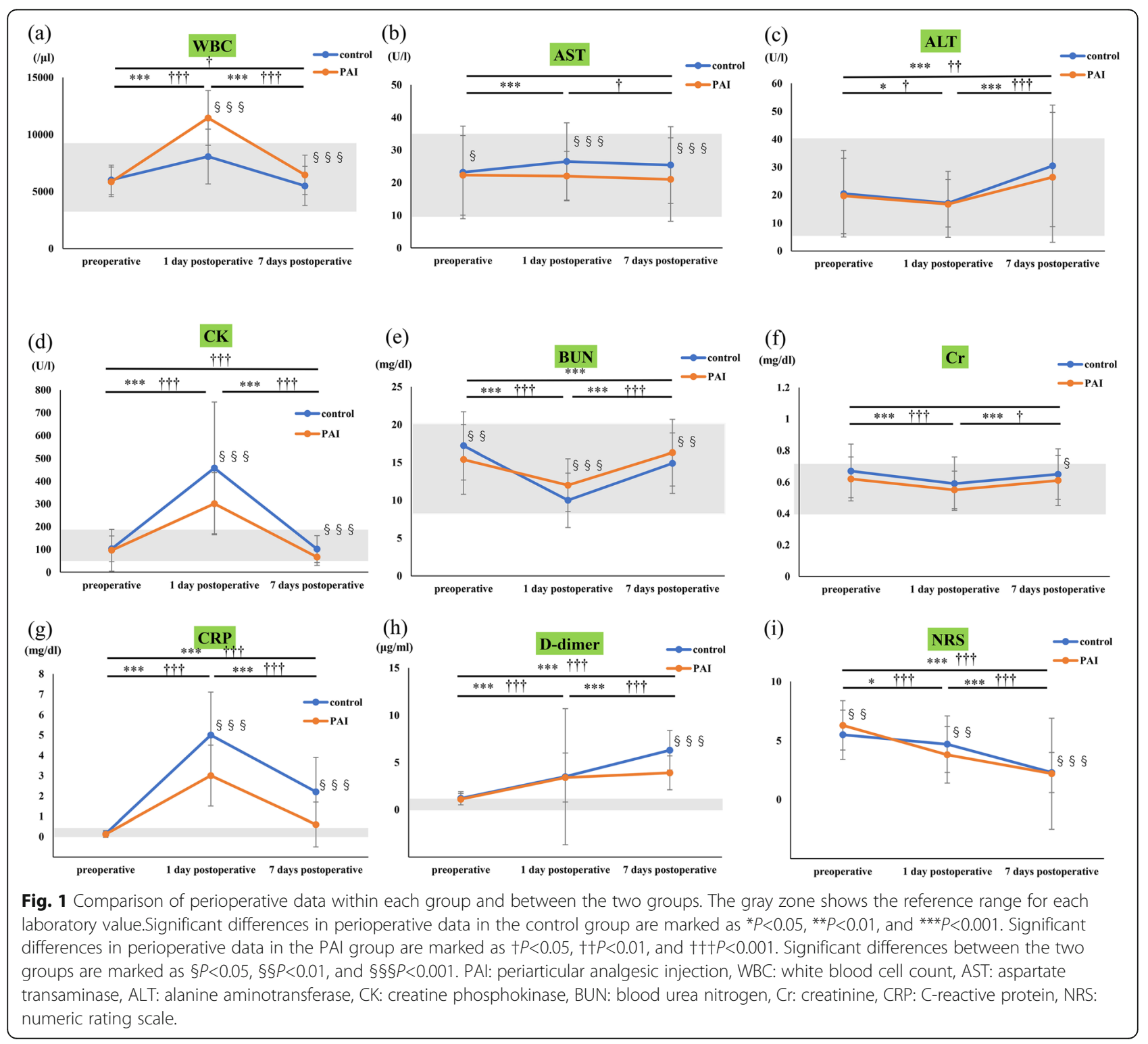


Table 3 Comparison of laboratory data between the PAl and control groups

\begin{tabular}{|c|c|c|c|c|c|c|c|c|c|}
\hline \multirow{2}{*}{$\begin{array}{l}\text { Laboratory } \\
\text { data }\end{array}$} & \multicolumn{3}{|l|}{ Preoperative } & \multicolumn{3}{|l|}{ POD 1} & \multicolumn{3}{|l|}{ POD 7} \\
\hline & $\begin{array}{l}\text { Control group } \\
(N=113)\end{array}$ & $\begin{array}{l}\text { PAl group } \\
(N=87)\end{array}$ & $p$ value & $\begin{array}{l}\text { Control group } \\
(N=113)\end{array}$ & $\begin{array}{l}\text { PAI group } \\
(N=87)\end{array}$ & $p$ value & $\begin{array}{l}\text { Control group } \\
(N=113)\end{array}$ & $\begin{array}{l}\text { PAI group } \\
(N=87)\end{array}$ & $p$ value \\
\hline$\overline{\mathrm{WBC}(/ \mu \mathrm{l})}$ & $6019.4 \pm 1653.6$ & $5851.7 \pm 1299.5$ & 0.7421 & $8072.6 \pm 1654.2$ & $11470.1 \pm 2409.0$ & $<0.0001$ & $5491.2 \pm 1274.9$ & $6464.4 \pm 1726.4$ & $<0.0001$ \\
\hline AST (U/l) & $23.3 \pm 14.2$ & $22.3 \pm 12.2$ & 0.0477 & $26.5 \pm 11.9$ & $22.0 \pm 7.6$ & $<0.0001$ & $25.4 \pm 11.8$ & $21 \pm 12.8$ & $<0.0001$ \\
\hline ALT (U/l) & $20.5 \pm 15.5$ & $19.7 \pm 13.5$ & 0.2959 & $17.1 \pm 8.5$ & $16.7 \pm 11.8$ & 0.0653 & $30.5 \pm 21.8$ & $26.4 \pm 23.3$ & 0.0766 \\
\hline CK $(\mathrm{U} / \mathrm{I})$ & $102.6 \pm 56.4$ & $96.1 \pm 92.2$ & 0.0584 & $457.8 \pm 289.2$ & $301.1 \pm 136.7$ & $<0.0001$ & $101.2 \pm 59.0$ & $66.0 \pm 36.8$ & $<0.0001$ \\
\hline BUN (mg/dl) & $17.2 \pm 4.5$ & $15.4 \pm 4.6$ & 0.005 & $10.0 \pm 3.6$ & $12.0 \pm 3.5$ & $<0.0001$ & $14.9 \pm 4.0$ & $16.3 \pm 4.4$ & 0.0091 \\
\hline $\mathrm{Cr}(\mathrm{mg} / \mathrm{dl})$ & $0.67 \pm 0.17$ & $0.62 \pm 0.14$ & 0.069 & $0.59 \pm 0.17$ & $0.55 \pm 0.12$ & 0.0742 & $0.65 \pm 0.16$ & $0.61 \pm 0.16$ & 0.0281 \\
\hline CRP $(\mathrm{mg} / \mathrm{dl})$ & $0.14 \pm 0.17$ & $0.12 \pm 0.15$ & 0.7851 & $5.0 \pm 2.1$ & $3.0 \pm 1.5$ & $<0.0001$ & $2.2 \pm 1.7$ & $0.6 \pm 1.1$ & $<0.0001$ \\
\hline $\begin{array}{l}\text { D-dimer }(\mu \mathrm{g} / \mathrm{ml}) \\
(\mathbf{【}(\mu \mathrm{g} / \mathrm{mL})\end{array}$ & $1.2 \pm 0.7$ & $1.1 \pm 0.6$ & 0.3573 & $3.5 \pm 7.2$ & $3.4 \pm 2.6$ & 0.5273 & $6.3 \pm 2.1$ & $3.9 \pm 1.8$ & $<0.0001$ \\
\hline
\end{tabular}

Values are expressed as the mean \pm standard deviation. $P A I$ periarticular analgesic injection, $P O D$ postoperative day, WBC white blood cell count, AST aspartate transaminase, ALT alanine aminotransferase, $C K$ creatine phosphokinase, BUN blood urea nitrogen, $C r$ creatinine, $C R P C$-reactive protein

consequently, a reduced risk of deep venous thrombosis (DVT).

Levobupivacaine, which is the S-enantiomer of bupivacaine, is a long-acting local anesthetic drug [13]. Compared to ropivacaine, levobupivacaine has a longer duration of action and the half-life is approximately $4 \mathrm{~h}$ [13-15]. Levobupivacaine has a wider margin of safety, in terms of cardiovascular and central nervous system adverse effects, compared with bupivacaine [16]. Therefore, levobupivacaine has been used in PAI [17, 18]. However, some previous studies have found that PAI (levobupivacaine and/or epinephrine) in THA did not reduce postoperative pain $[17,18]$. Conversely, our study demonstrated lower NRS scores in the PAI group on PODs 1 and 7, which indicates that the corticosteroid may have had an effect on postoperative pain.

Previous studies reported that trauma and surgery, including THA, cause the release of interleukin (IL)-6,

Table 4 Correlations between D-dimer levels on POD 7 and data on POD $1(N=200)$

\begin{tabular}{lllll}
\hline & & \multicolumn{2}{l}{$\mathbf{9 5 \% \mathrm { Cl }}$} & \\
\cline { 3 - 4 } & $\boldsymbol{r}$ & Lower & Upper & $\boldsymbol{p}$ value \\
\hline NRS & 0.1558 & 0.0175 & 0.2884 & 0.0275 \\
WBC & -0.4652 & -0.5673 & -0.3490 & $<0.0001$ \\
AST & 0.2353 & 0.0998 & 0.3622 & $<0.0001$ \\
ALT & 0.0525 & -0.0869 & 0.1899 & 0.4604 \\
CK & 0.2718 & 0.1382 & 0.3956 & $<0.0001$ \\
BUN & -0.1694 & -0.3010 & -0.0314 & 0.0166 \\
Cr & -0.0284 & -0.1665 & 0.1108 & 0.6899 \\
CRP & 0.3545 & 0.2269 & 0.4701 & $<0.0001$ \\
D-dimer & 0.3359 & 0.2068 & 0.4535 & $<0.0001$ \\
\hline
\end{tabular}

$P O D$ postoperative day, $P A l$ periarticular analgesic injection, $C l$ confidence interval, NRS numeric rating scale, WBC white blood cell count, AST aspartate transaminase, ALT alanine aminotransferase, $C K$ creatine phosphokinase, BUN blood urea nitrogen, $\mathrm{Cr}$ creatinine, CRP C-reactive protein causing local inflammation at the site of injury [19-21]. CRP is an acute-phase protein that increases after inflammation and is a marker that reflects the severity of inflammation $[19,22]$. The release of IL-6 during inflammation leads to the production of CRP [19]. CK is an energy production enzyme in the mitochondria and is primarily found in muscle tissues [23]. CK elevation is a feature of muscle inflammation or damage [24]. Corticosteroids have an anti-inflammatory effect, via the inhibition of the synthesis of phospholipase A2, thereby reducing the production of the pro-inflammatory derivatives of arachidonic acid, e.g. IL-1, IL-2, IL-6, and tumor necrosis factor $(\mathrm{TNF}-\alpha)[25,26]$. An anti-inflammatory effect of glucocorticoids (e.g., reduction of IL-6 in the drain fluid and CRP) in total knee arthroplasty has been reported [27]. Postoperative CRP and CK levels were lower in the PAI group than in the control group, owing to the anti-inflammatory effect of the corticosteroid in this study.

Triamcinolone acetonide was the corticosteroid used in this study, which is an intermediate-acting glucocorticoid with a half-life between 18 and $36 \mathrm{~h}$ [25, 28]. Intramuscular administration of triamcinolone acetonide provides a slow absorption and prolonged duration [28, 29]. In this study, CRP levels and CK levels on POD 7 were lower in the PAI group than in the control group. Surprisingly, in the PAI group, CK levels were significantly lower on POD 7 than before surgery. Therefore, PAI containing triamcinolone acetonide may have a prolonged anti-inflammatory effect after THA, for at least 7 days postoperatively.

Postoperative pain is considered a form of acute pain owing to surgical trauma with an inflammatory reaction and initiation of an afferent neuronal barrage [30]. Therefore, reducing inflammation is important for reducing postoperative pain. Additionally, postoperative inflammation affects the immediate functional recovery 
after THA [31], and pain management following THA is important for early postoperative rehabilitation [32]. This study demonstrated the analgesic effect of PAI containing a corticosteroid on POD 7 owing to the antiinflammatory effect of a corticosteroid that has a long duration of activity [28, 29]. Therefore, the analgesic effect of PAI containing a corticosteroid may accelerate early postoperative rehabilitation.

DVT and pulmonary embolus are potential lifethreating complications after THA, and their prevention is a universal quality improvement initiative [33, 34]. Ddimer is a degradation product of a cross-linked fibrin blood clot [35], and the elevation of D-dimer levels is caused by acute venous thromboembolism, recent major surgery, hemorrhage, trauma, pregnancy, and cancer [35]. A D-dimer test is a simple and useful method for diagnosing DVT, because the incorporation of a Ddimer test into a clinical diagnostic strategy can identify DVT without ultrasonography [36, 37]. Antithrombotic drugs, an intermittent compression device, pneumatic foot pumps, graduated compression stockings, and early ambulation are methods for preventing DVT in patients after surgery [38, 39]. Additionally, early ambulation prevents the development of high postoperative $\mathrm{D}$-dimer levels [40]. In our study, walking training began after POD 1 in both groups; thus, early ambulation had no effect on the D-dimer levels on POD 1. Rather, D-dimer levels on POD 1 were only affected by the surgery [35]. Hence, there was no significant difference between the D-dimer levels of the two groups on POD 1 . On the other hand, the analgesic and anti-inflammatory effects of corticosteroid PAI from POD 1 may accelerate early ambulation. Therefore, the D-dimer levels were significantly lower in the PAI group than in the control group on POD 7.

Glucocorticoids can stimulate the bone marrow to produce more granulocytes, inhibit neutrophil apoptosis, and impair the migration of granulocytes to sites of inflammation or infection through the vasculature [41-43]. This results in increased numbers of circulating neutrophils [41-43]. In this study, the postoperative WBC was significantly higher in the PAI group than in the control group, and the WBC in the PAI group was significantly higher on POD 7 than before surgery. The postoperative WBC elevation in the PAI group may be due to the prolonged effect of the corticosteroid on granulocytes. Our results were contradictory because the postoperative WBC increased and the postoperative CRP levels decreased in the PAI group, even though WBC and CRP are both markers of inflammation [19, 22, 44]. The effect of increased number of circulating neutrophils may be greater than the effect of lowering WBC by antiinflammation using the corticosteroid.
AST is found in the liver, heart, muscle, kidneys, brain, and blood cells, [45] while ALT is found in the plasma and other organs; however, most ALT is found in the liver [45].

In our study, postoperative AST levels were lower in the PAI group than in the control group. There were no significant differences between the pre and postoperative AST levels within the PAI group. Postoperative ALT levels were not significantly different between the two groups. Levobupivacaine and corticosteroids are mainly metabolized by the liver [46, 47]; normal postoperative ALT levels in both groups indicate that there was no drug hepatopathy following THA with or without corticosteroid PAI. Thus, the anti-inflammatory effects of the corticosteroid may have prevented muscle damage and influenced AST levels in the PAI group, as observed with CK.

BUN and $\mathrm{Cr}$ are biomarkers of kidney function [48]. The differences in BUN and Cr levels on POD 7 were inconsistent between the groups. Both $\mathrm{BUN}$ and $\mathrm{Cr}$ levels were within their reference ranges on POD 7. The metabolization of levobupivacaine and corticosteroids occurs primarily in the liver [46, 47]; therefore, it was assumed that the PAI containing a corticosteroid did not directly produce any drug-induced kidney injury.

In the PAI group, the NRS score, CPK, CRP levels on POD 1 were lower than those in the control group, which reflects the analgesic and anti-inflammatory effects of the PAI containing a corticosteroid. In addition, pain management and reducing inflammation following THA are important for early postoperative rehabilitation as they can prevent the elevation of postoperative Ddimer levels and reduce the risk of DVT [31, 32, 39, 40]. In all hips in both groups, the NRS score, CPK, and CRP levels on POD 1 showed significant positive correlations with D-dimer levels on POD 7. Therefore, a PAI containing a corticosteroid is a useful method for pain management and for reducing inflammation following THA. D-dimer levels tend to rise after surgery, and the halftime is quite long $[35,49]$. Hence, the D-dimer levels on POD 1 may have affected the D-dimer levels on POD 7, perhaps resulting in the significant positive correlation between D-dimer levels on POD 1 and those on POD 7 in this study. As for the WBC, in the PAI group, the WBC on POD 1 was higher than that in the control group because the WBC on POD 1 was elevated, owing to the effect of the corticosteroid on circulating neutrophils. The D-dimer levels on POD 7 in the PAI group were lower than those in the control group, likely due to early ambulation. These may result in the significant negative correlation between the WBC on POD 1 and D-dimer levels on POD 7.

There are several limitations in our study. First, CRP was the only inflammatory marker investigated. Other 
indices to evaluate inflammation, such as IL-6, were lacking. However, evaluating CRP may be sufficient for investigating the grade of inflammation because CRP is highly correlated with IL-6 [50]. Second, postoperative functional performance was not investigated. Therefore, we could not investigate an association between postoperative functional performance and D-dimer levels. In the future, assessments of postoperative functional performance are needed. Third, there was no assessment of the incidence of DVT, which is associated with elevated D-dimer levels, using computed tomographic scanning or ultrasonography [51]. Although imaging tests are not always necessary for the diagnosis of DVT [37], imaging tests may be needed to determine whether PAI containing a corticosteroid accurately reduces DVT in future studies. Finally, the contents of the PAI in this study were a corticosteroid and levobupivacaine. A group that receives a PAI containing only a corticosteroid, without levobupivacaine, may be necessary to definitively investigate the anti-inflammatory effect of corticosteroids.

\section{Conclusions}

PAI containing a corticosteroid was found to be an effective treatment for pain and inflammation following THA. Considering the lower postoperative D-dimer levels observed in the PAI group, the analgesic and antiinflammatory effects of corticosteroid PAI may have the potential to accelerate early ambulation and reduce the risk of DVT.

\section{Abbreviations \\ ALT: Alanine aminotransferase; AST: Aspartate transaminase; BMI: Body mass index; BUN: Blood urea nitrogen; CK: Creatine phosphokinase; $\mathrm{Cr}$ : Creatinine; CRP: C-reactive protein; DVT: Deep venous thrombosis; IL: Interleukin; NRS: Numeric Rating Scale; NSAID: Nonsteroidal anti-inflammatory drugs; PAI: Periarticular analgesic injection; POD: Postoperative day; THA: Total hip arthroplasty; TNF: Tumor necrosis factor; WBC: White blood cell count}

\section{Acknowledgements}

Not applicable.

\section{Authors' contributions}

AH initiated the study, analyzed the data, wrote the first draft of the manuscript, and contributed significantly to the final draft of the manuscript. MS initiated and designed the study, collected data, helped with the first draft of the manuscript, and contributed significantly to the final draft of the manuscript. HH, SK, SE, and MU initiated and designed the study and collected data. MM collected data, helped with the first draft of the manuscript, contributed significantly to the final draft of the manuscript, and supervised the study. All authors read and approved the final manuscript.

\section{Funding}

None.

\section{Availability of data and materials}

The datasets used and/or analyzed during the current study are available from the corresponding author on reasonable request.

\section{Ethics approval and consent to participate}

The study was approved by the Ethics Committee Saga University Hospital. All patients provided informed consent based on an opt-out policy prior to participation in this study (reference number: 2020-06-R-06).
Consent for publication

Not applicable.

\section{Competing interests}

The authors declare that they have no competing interests.

\section{Author details}

'Department of Orthopaedic Surgery, Faculty of Medicine, Saga University, Nabeshima 5-1-1, 849-8501 Saga, Japan. ${ }^{2}$ Research Center of Arthroplasty, Faculty of Medicine, Saga University, Nabeshima 5-1-1, 849-8501 Saga, Japan.

Received: 3 September 2020 Accepted: 14 December 2020 Published online: 06 January 2021

\section{References}

1. Learmonth ID, Young C, Rorabeck C. The operation of the century: total hip replacement. Lancet. 2007;370:1508-19.

2. Halawi MJ, Jongbloed W, Baron S, Savoy L, Williams VJ, Cote MP. Patient dissatisfaction after primary total joint arthroplasty: the patient perspective. J Arthroplasty. 2019;34:1093-6.

3. Hamilton DF, Lane JV, Gaston P, Patton JT, Macdonald D, Simpson AH, et al. What determines patient satisfaction with surgery? A prospective cohort study of 4709 patients following total joint replacement. BMJ Open. 2013;3: e002525. doi:https://doi.org/10.1136/bmjopen-2012-002525.

4. Kehlet $\mathrm{H}$, Jensen TS, Woolf CJ. Persistent postsurgical pain: risk factors and prevention. Lancet. 2006;367:1618-25.

5. Singelyn FJ, Ferrant T, Malisse MF, Joris D. Effects of intravenous patientcontrolled analgesia with morphine, continuous epidural analgesia, and continuous femoral nerve sheath block on rehabilitation after unilateral total-hip arthroplasty. Reg Anesth Pain Med. 2005;30:452-7.

6. Hirasawa N, Kurosaka K, Nishino M, Nakayama T, Matsubara M, Tsukada S. No clinically important difference in pain scores after THA between periarticular analgesic injection and placebo: a randomized trial. Clin Orthop Relat Res. 2018;476:1837-45.

7. Ma HH, Chou TA, Tsai SW, Chen CF, Wu PK, Chen WM. The efficacy of intraoperative periarticular injection in Total hip arthroplasty: a systematic review and meta-analysis. BMC Musculoskelet Disord. 2019;20:269.

8. Andersen $L$, Kehlet $H$. Analgesic efficacy of local infiltration analgesia in hip and knee arthroplasty: a systematic review. Br J Anaesth. 2014;113:360-74.

9. Pandazi A, Kanellopoulos I, Kalimeris K, Batistaki C, Nikolakopoulos N, Matsota $P$, et al. Periarticular infiltration for pain relief after total hip arthroplasty: a comparison with epidural and PCA analgesia. Arch Orthop Trauma Surg. 2013;133:1607-12.

10. Liu W, Cong R, Li X, Wu Y, Wu H. Reduced opioid consumption and improved early rehabilitation with local and intraarticular cocktail analgesic injection in total hip arthroplasty: a randomized controlled clinical trial. Pain Med. 2011;12:387-93.

11. Kim JI, Kim YT, Jung HJ, Lee JK. Does adding corticosteroids to periarticular injection affect the postoperative acute phase response after total knee arthroplasty? Knee. 2020;27:493-9.

12. Rodriguez CS. Pain measurement in the elderly: a review. Pain Manag Nurs. 2001:2:38-46.

13. Niemeläinen M, Kalliovalkama J, Aho AJ, Moilanen T, Eskelinen A. Single periarticular local infiltration analgesia reduces opiate consumption until 48 hours after total knee arthroplasty. a randomized placebo-controlled trial. involving 56 patients. Acta Orthop. 2014;85:614-9.

14. Tammachote N, Kanitnate S, Manuwong S, Panichkul P. Periarticular multimodal drug injection is better than single anesthetic drug in controlling pain after total knee arthroplasty. Eur J Orthop Surg Traumatol. 2018;28:667-75

15. Burlacu CL, Buggy DJ. Update on local anesthetics: Focus on levobupivacaine. Ther Clin Risk Manag. 2008;4:381-92.

16. Stewart J, Kellett N, Castro D. The central nervous system and cardiovascular effects of levobupivacaine and ropivacaine in healthy volunteers. Anesth Analg. 2003;97:412-6.

17. Dobie I, Bennett D, Spence DJ, Murray JM, Beverland DE. Periarticular local anesthesia does not improve pain or mobility after THA. Clin Orthop Relat Res. 2012:470:1958-65.

18. Murphy TP, Byrne DP, Curtin P, Baker JF, Mulhall KJ. Can a periarticular levobupivacaine injection reduce postoperative opiate consumption during primary hip arthroplasty? Clin Orthop Relat Res. 2012;470:1151-7. 
19. Kuchálik J, Magnuson A, Tina E, Gupta A. Does local infiltration analgesia reduce peri-operative inflammation following total hip arthroplasty? a randomized, double-blind study. BMC Anesthesiol. 2017;17:63.

20. Reikeras $\mathrm{O}$, Borgen $\mathrm{P}$, Reseland JE, Lyngstadaas SP. Changes in serum cytokines in response to musculoskeletal surgical trauma. BMC Res Notes. 2014;7:128.

21. Kugisaki H, Sonohata M, Komine M, Tsunoda K, Someya S, Honke H, et al. Serum concentrations of interleukin- 6 in patients following unilateral versus bilateral total knee arthroplasty. J Orthop Sci. 2009;14:437-42.

22. Vreugdenhil B, van der Velden WJFM, Feuth $T$, Kox M, Pickkers P, van de Veerdonk FL, et al. Moderate correlation between systemic IL-6 responses and CRP with trough concentrations of voriconazole. Br J Clin Pharmacol. 2018;84:1980-8.

23. Leverenz D, Zaha O, Crofford LJ, Chung CP. Causes of creatine kinase levels greater than $1000 \mathrm{IU} / \mathrm{L}$ in patients referred to rheumatology. Clin Rheumatol. 2016;35:1541-7.

24. laccarino L, Pegoraro E, Bello L, Bettio S, Borella E, Nalotto L, et al. Assessment of patients with idiopathic inflammatory myopathies and isolated creatin-kinase elevation. Auto Immun Highlights. 2014;5:87-94.

25. Jermak CM, Dellacroce JT, Heffez J, Peyman GA. Triamcinolone acetonide in ocular therapeutics. Surv Ophthalmol. 2007;52:503-22.

26. Goldstein RA, Bowen DL, Fauci AS. Inflammation: Basic Principles and Clinical Correlates. In: Gallin Jl, Goldstein IM, Snyderman R, editors. New York: Raven Press; 1992. pp. 1061-81.

27. Ikeuchi M, Kamimoto Y, Izumi M, Fukunaga K, Aso K, Sugimura N, et al. Effects of dexamethasone on local infiltration analgesia in total knee arthroplasty: a randomized controlled trial. Knee Surg Sports Traumatol Arthrosc. 2014;22:1638-43.

28. Salerno A, Hermann R. Efficacy and safety of steroid use for postoperative pain relief. update and review of the medical literature. J Bone Joint Surg Am. 2006;88:1361-72.

29. Coll S, Monfort N, Alechaga É, Matabosch X, Pérez-Mañá C, Ventura R. Additional studies on triamcinolone acetonide use and misuse in sports: elimination profile after intranasal and high-dose intramuscular administrations. Steroids. 2019;151:108464.

30. Gupta A, Kaur K, Sharma S, Goyal S, Arora S, Murthy RS. Clinical aspects of acute post-operative pain management \& its assessment. J Adv Pharm Technol Res. 2010;1:97-108.

31. Hall GM, Peerbhoy D, Shenkin A, Parker CJ, Salmon P. Relationship of the functional recovery after hip arthroplasty to the neuroendocrine and inflammatory responses. Br J Anaesth. 2001;87:537-42.

32. Nakai T, Nakamura T, Nakai T, Onishi A, Hashimoto K. A study of the usefulness of a periarticular multimodal drug cocktail injection for pain management after total hip arthroplasty. J Orthop. 2013;10:5-7.

33. Memtsoudis SG, Pumberger M, Ma Y, Chiu YL, Fritsch G, Gerner $P$, et al. Epidemiology and risk factors for perioperative mortality after total hip and knee arthroplasty. J Orthop Res. 2012;30:1811-21.

34. Lachiewicz PF. Comparison of ACCP and AAOS guidelines for VTE prophylaxis after total hip and total knee arthroplasty. Orthopedics. 2009;32:74-8.

35. Scarvelis D, Wells PS. Diagnosis and treatment of deep-vein thrombosis. CMAJ. 2006;175:1087-92.

36. Wada H, Kobayashi T, Abe Y, Hatada T, Yamada N, Sudo A, et al. Elevated levels of soluble fibrin or d-dimer indicate high risk of thrombosis. J Thromb Haemost. 2006;6:1253-8.

37. Wells PS, Anderson DR, Rodger M, Forgie M, Kearon C, Dreyer J, et al. Evaluation of D-Dimer in the diagnosis of suspected deep-vein thrombosis. N Engl J Med. 2003;349:1227-35.

38. Wade R, Sideris E, Paton F, Rice S, Palmer S, Fox D, et al. Graduated compression stockings for the prevention of deep-vein thrombosis in postoperative surgical patients: a systematic review and economic model with a value of information analysis. Health Technol Assess. 2015;19:1-220.

39. Pearse EO, Caldwell BF, Lockwood RJ, Hollard J. Early mobilisation after conventional knee replacement may reduce the risk of postoperative venous thromboembolism. J Bone Joint Surg Br. 2007;89:316-22.

40. Nakao S, Takata S, Uemura H, Nakano S, Egawa H, Kawasaki Y, et al. Early ambulation after total knee arthroplasty prevents patients with osteoarthritis and rheumatoid arthritis from developing postoperative higher levels of Ddimer. J Med Invest. 2010;57:146-51.

41. Fauci AS, Dale DC, Balow JE. Glucocorticosteroid therapy: mechanisms of action and clinical considerations. Ann Intern Med. 1976;84:304-15.
42. Cox G. Glucocorticoid treatment inhibits apoptosis in human neutrophils. Separation of survival and activation outcomes. J Immunol. 1995;154:4719-25.

43. Meagher LC, Cousin JM, SeckI JR, Haslett C. Opposing effects of glucocorticoids on the rate of apoptosis in neutrophilic and eosinophilic granulocytes. J Immunol. 1996;156:4422-8.

44. Andersson M, Andersson RE. The appendicitis inflammatory response score: a tool for the diagnosis of acute appendicitis that outperforms the Alvarado score. World J Surg. 2008;32:1843-9.

45. Kim HJ, Kim SY, Shin SP, Yang YJ, Bang CS, Baik GH, et al. Immunological measurement of aspartate/alanine aminotransferase in predicting liver fibrosis and inflammation. Korean J Intern Med. 2020;35:320-30.

46. Bajwa SJ, Kaur J. Clinical profile of levobupivacaine in regional anesthesia: A systematic review. J Anaesthesiol Clin Phamacol. 2013;29:530-9.

47. Moore CD, Roberts JK, Orton CR, Murai T, Fidler TP, Reilly CA, et al. Metabolic pathways of inhaled glucocorticoids by the CYP3A enzymes. Drug Metab Dispos. 2013;41:379-89.

48. Gowda S, Desai PB, Kulkarni SS, Hull W, Math AA, Vernekar SN. Markers of renal function tests. N Am J Med Sci. 2010;2:170-3.

49. Amiral J, Fareed J. Thromboembolic diseases: biochemical mechanisms and new possibilities of biological diagnosis. Semin Thromb Hemost. 1996;22:41-8.

50. Garvin P, Nilsson E, Ernerudh J, Kristenson M. The joint subclinical elevation of CRP and IL-6 is associated with lower health-related quality of life in comparison with no elevation or elevation of only one of the biomarkers. Qual Life Res. 2016;25:213-21.

51. Halaby R, Popma CJ, Cohen A, Chi G, Zacarkim MR, Romero G, et al. D-Dimer elevation and adverse outcomes. J Thromb Thrombolysis. 2015;39:55-9.

\section{Publisher's Note}

Springer Nature remains neutral with regard to jurisdictional claims in published maps and institutional affiliations.

Ready to submit your research? Choose BMC and benefit from:

- fast, convenient online submission

- thorough peer review by experienced researchers in your field

- rapid publication on acceptance

- support for research data, including large and complex data types

- gold Open Access which fosters wider collaboration and increased citations

- maximum visibility for your research: over $100 \mathrm{M}$ website views per year

At $\mathrm{BMC}$, research is always in progress.

Learn more biomedcentral.com/submissions 